\title{
Marketing Mix Factors Affecting Chinese Shabu Suki Chaina
}

\author{
Shen yun Gao and Watchara yeesoontes \\ Gaduate School of Business Administration Kasembundit University, Bangkok
}

\begin{abstract}
The purpose of this research was to investigate the behavior of consumers in choosing Chinese Shabu suki and to study the marketing mix that affects Chinese shabu suki. The 400 questionnaires were used to collect data and used statistical data to analyze the data including mean, percentage, mean, and hypothesis test. One-way ANOVA and regression analysis. Hypothesis testing. Regression showed that most respondents were female, 19-30 years of age, graduated with bachelor's degree or equivalent. Have a company employee Monthly income 10,001-20,000 Baht Most of the time, they like to have a clear soup between 18:00 - 24:00 hrs. Duration of service: 61-90 minutes. Marketing mix factors influencing the choice of Chinese crab meat. Products Focus on the quality of food. Affordable price. Distribution focuses on Comfortable travel and marketing promotion focus on the cleanliness of the store and the container used.
\end{abstract}

Keywords: consumer behavior Comprehensive Chinese market

\section{Introduction}

Food is the fourth factor that fundamentally influences human life. So man gives The importance of eating is a popular food nowadays. Variety of types and types of foods vary. They can be classified and kind. Food by country and region. (Wongsakon komprm, BE.2553: 1)Chinese food is one of the foods with long history and culture. And Chinese people can. Maintain the culture of Chinese food completely. Chinese food is focused on freshness. Of raw materials Cook The food is completely useful. Popular as a drug. As a result, Chinese food is world famous.(Chaina study centre WLC, BE2558)Chinese people in each region have a different culture of eating and food taste. And when it comes to food. Of course, the first thing to remember is to escape the food with spicy or hot tea. Whether it is fried foods, curry soup, boiled pot, they are pure and chili to taste.

Comes from a combination of The meaning of the taste is both spicy and tea sure enough. It is the main flavor of the food. And what makes tea from chili is a kind of chili. This type of chili is popular and famous in the county. When mixed with chili, it will cause tea and spicy chili, it is popular with pots and lights and soup. It can also be used for other purposes such as grilled and fried foods such as chicken, fried squid, fried chicken and grilled. From this point of view, it is interesting for the study to study the market mix factors affecting Chinese eating behavior. It is the decision to open a Chinese Shabu Suki restaurant in Thailand.

\section{Purpose of Study}

1. To study the behavior of consumers in eating Chinese Shabu.

2. To study the marketing mix factors that affect the selection of Chinese Shabu.

- Hypothesis of the study

1. Different personal factors affect the different choices of Chinese crabs.

2. Different consumer behavior factors affect the different types of Chinese crab sausage.

The marketing mix has an influence on the choice of Chinese crabmeat.

\section{Scope of Study}

Consumer Behavior $(6 \mathrm{w}+\mathrm{H})$ and Product Marketing, Price, Place and Promotion. The populations used in the study are consumers who eat Chinese food, Shabu shop, Suki MK restaurant or any other shop that is a pot of fire. In Bangkok, there were 400 Duration of study BE2559-January BE 2560 


\section{Conceptual framework in education}

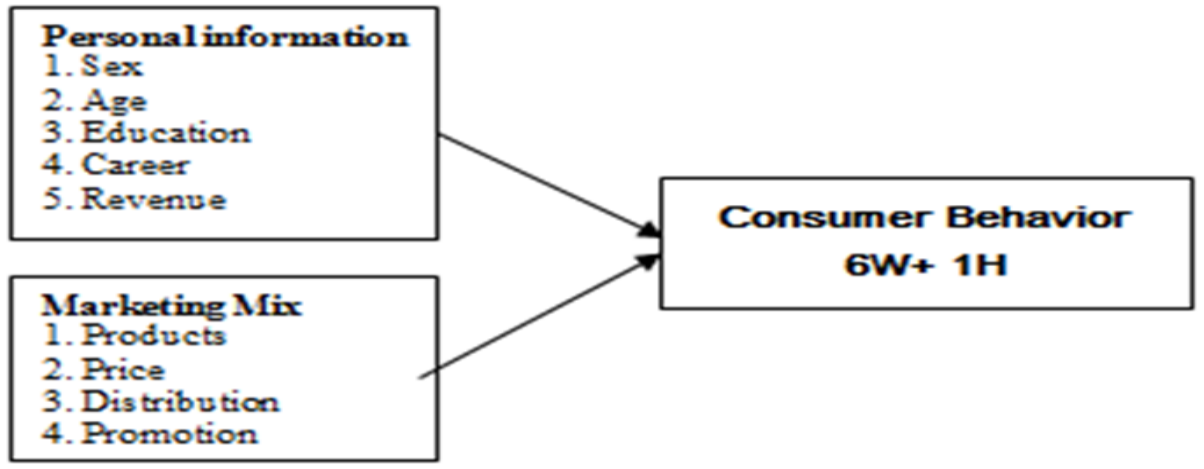

\section{Research Methodology}

Population used in education a person who used to serve Chinese restaurant, shabu shop, MK shop or any other shop that is a pot of fire. In Bangkok 400 samples selected.

Procedures Data Collection

In order to complete the study, we have to collect the following information:

1. Data collected from Studying from various sources, including textbooks.

And other research findings Associated

2. Information obtained from Responding Of the target audience And get yourself back. Complete the check. To ensure that the questionnaire is complete and can be analyzed for further information.

\section{Data Analysis}

Processed data from the questionnaire by computer program by Percentage and Mean. Microsoft Excel, a program for pie chart and bar chart. Describe the result The results from the chart are presented for analysis of the variables

\section{Research Result}

Studies of marketing mix factors affecting Chinese shabu shake eating behavior. The purpose of this study was to investigate the behavior of consumers and to study the marketing mix that influenced the choice of Chinese sushi. The 400 questionnaires were used as a tool to collect data and used statistical data to analyze data such as mean, percentage, mean, and hypothesis. One-way ANOVA and Regression analysis were used. The information can be summarized as follows.

\section{Personal Information}

The majority of respondents were female, aged 19-30 years, with a bachelor's degree or equivalent. Career Monthly income 10,001-20,000 Baht Most people prefer clear broth. 18: 00-24: 00 To use Number of people who eat 4 or more people per session. Duration of service 61-90 minutes.

\section{Summarize Factors Marketing Mix}

- Products It was found that the overall mean of the market mix factors for the selection of Chinese crab meat Products The average level (3.14) is important for the decision to eat Chinese Shabu. 4 items consist of food quality (average $=3.3$.), Variety of food $($ Average $=3.22)$ and taste $($ average $=3.16)$. (Average $=3.16)$, respectively.

- Price, it was found that the average level of significance of the marketing mix was found to be moderate $($ mean $=3.11)$. Chinese sausage The average price was $3.20($ average $=3.20)$. 
- Distribution It was found that the overall mean of market mix factors influenced the selection of Chinese Shabu. The average place (average $=2.95$ ) gave importance to the decision to eat Chinese Shabu. The average level of 4 items was convenient (average $=3.21$ ). (Mean $=2.84$ ) and close to the stop (average $=2.82$ ), respectively.

- Marketing promotion It was found that the overall mean of market mix factors influenced the selection of Chinese Shabu. Marketing promotion The average level (3.07) was important for the decision to eat Chinese Shabu. Medium (= 3.21) Medium (=3.14) Medium (= Average $)=3.14$ Recommended menu $($ Average $=3.03)=$ 2.98) Lucky discount (average $=2.87$ ), ads (average $=2.73$ ), respectivel

\section{Discussion of Results}

Studies of marketing mix factors affecting Chinese shabu shake eating behavior. The participants discussed the following issues.

Hypothesis 1: Different personal factors affect different investment decisions. The ANOVA statistics show that clients with gender, age, occupation, average income per month Differences affect the selection of different chapel service. Consistent with the research of kanongping malaikul (BE2554), the study on consumer service marketing factors in choosing restaurants and pubs found that individual consumers consisted of gender, age, occupation, average income per month different It affects the decision to use the restaurant and pub.

Hypothesis 2: Different consumer behavior factors influence different consumption decisions. Test results using ANOVA statistics showed that the customer known Sichuan light pot. Differences affect the selection of different chapel service. According to Rossukon Rosshaem (BE 2010), the study of factors affecting behavior and satisfaction of customers who use the restaurant service in the middle market for farmers. In Ayutthaya, individual consumers are characterized by their different Sichuan pots. Affecting the decision to use the restaurant service in the central market for farmers. Phra Nakhon Si Ayutthaya Province

Hypothesis 3: Marketing Mix Factors Affecting Chinese Shabu SuitThe results of the experiment using the regression showed that the marketing mix of the food quality factors influenced the decision to use the medium cassava firewood cassava (JA) pumjan (BE2554) study. Influence on the decision to use Korean BBQ restaurant in Ubon Ratchathani Municipality. Ubon Ratchathani Factors influencing the behavior of using Korean BBQ restaurant. Variety of menu items At the moderate levelPrice marketing mix The inexpensive price had an influence on the decision to use the medium cassava firewood casserole served with the Manirate Sduwiti (BE2553) study on factors and behavior influencing the selection of Ban Yum restaurant. Price marketing mix The issue of food prices clearly. At the moderate level

Marketing mix factor. Travel issues have influenced decision making.Comply with Manirate Sduwiti (BE 2010)The factors and behavior influencing the selection of Ban Yum restaurant were as follows: The location of the shop can be easily reached. There is enough parking space. At the moderate level. Marketing Mix Factors Influencing Decision Making Using Test Results by Using Regression Analysis. Marketing Mix Factors. Influence the decision to use the service.

\section{Suggestions from the Study}

1. Personal factors in terms of gender, age, occupation, salary, and occupation differed significantly. Therefore, in the opening of the Chinese restaurant, Sichuan Sichuan Pay attention to gender factors in terms of age, occupation, salary.

2. Consumer Behavior Factors The difference in Sichuan pots varies considerably. So, in the Chinese sushi casserole named Sichuan fire pot. The importance of the Sichuan pots should be emphasized. For example, advertising creates relationships with customers.

3. Marketing Mix Factor Products Food quality issues. Price issues are clearly defined food prices. Distribution The location of the shop can be easily reached. There is enough parking space. Influence on 
the decision to use crab shampoo. So, in the opening of the Chinese crabs,

Sichuan should focus on these factors.

\section{Suggestions for the Next Study}

4. Further information should be sought by in-depth interviews. In the personnel level, select representatives of each group, including in-depth interviews. Management of related agencies such as Managing Director, Chief Executive, etc. Get more insights

5. For this study Selected Population-Specific Populations So for the next study. The population should change. To compare the results of the results analysis. For the benefit of bringing the result to a better implementation.

\section{References}

[1] Kotler, Philip. (1967) principles of Marketing Management. Upper Saddle River, NJ: Prentice Hall.

[2] Kanokpict malaikul (BE.2554 ). Marketing Service Factors Affect Consumers in Choosing Restaurants and Pubs in Amphoe Muang Payao Province. Master of Business Administration Chiang Rai Rajabhat University.

[3] Jumrate pumjan (BE. 2554) Marketing strategies that influence the decision to use Korean roast beef restaurants.. Master of Business Administration Ubon Ratchathani Rajabhat University.

[4] Manirate Saduwitichai(BE.2553) Factors and Behaviors Influencing the Selection of Ban Yum Restaurant.Master of Business Administration Kasetsart University.

[5] Rossukong Roschaem (BE2553) Factors Affecting Behavior and Satisfaction of Customers who Use the Restaurant Service in the Central Market for Farmers in Phranakhon Si Ayutthaya Province. Business Administration Ayutthaya Phranakhon Si Ayutthaya, Rajabhat University. 